\title{
Approach for operation and expansion of quarries prone for blast vibration issues
}

\author{
HS Venkatesh and G Gopinath \\ National Institute of Rock Mechanics \\ Bengaluru, India \\ rbeenirm@gmail.com
}

\begin{abstract}
Ground vibration resulting from blasting, has become a critical environmental issue with the increasing mining activities in areas close to human settlements and many a times the locals resist the blasting even though it is not causing damage to their structures. In general, apprehensions or perceptions have been increasing probably because of awareness or genuine concern or vested interest. This paper presents the measurements and analysis of blast induced ground vibration at one of the limestone quarries in Southern India, where the villagers had the apprehension with regard to adverse impact of blasting on their water head tank and other permanent structures within the village. Conventionally these kind of complaints conclude with field studies leading to establishment of a site specific predictor equation and arriving at the permissible maximum charge per delay for the limit as per the prevailing norms. However, this paper goes beyond by providing a means of representing the field observations in a simple form understandable by all the stake holders for ensuring a permanent solution. The approach can be used as a guideline for addressing vibration issues in many operating or proposed quarries.
\end{abstract}

Keywords-blast vibration; vibration issues; vibration approach; limestone mine blast vibration.

\section{INTRODUCTION}

Environmental problems resulting from ground vibration and air blast have been considered with and discussed frequently in various industries associated with mining, construction, quarrying, pipe lines, etc. where blasting is an integral operation. Complaints with regard to ground vibrations and noise from villages neighbouring operating mines have increased probably due to expansion of villages and or due to mines moving closer to these because of advancing benches. In both cases the aggrieved party happens to be the villagers. One basic complaint that is predominant is that people complain that they are hearing excessive noise or rattling of windows and that the vibrations are high. Secondly the complaints are that the cracks in the structures are because of indiscriminate blasting by the mining companies. Therefore, it is imperative that determination of safe maximum charge per delay for the critical distances and its compliance is extremely important for elimination of these environmental problems/complaints. Although many research/field studies have been carried out in the past to minimize environmental issues due to blasting, unfortunately a general approach or a practical enforceable solutions seems to be evasive. Keeping this in mind the authors present a simple practical approach to address vibration problems through a field study.

\section{SiTE DETAILS}

The field measurements were carried out at a limestone quarry in southern India where the authors were asked to carry out the studies due to complaint from the nearby villages to the district administration [1]. The limestone for the plant is fed from two separate quarries (South pit and North pit). The south pit is located near a village comprising of about five hundred houses including few mud houses. The radial distance between the working face and the nearest structures like houses, water tank, labour colony are $560 \mathrm{~m}, 430 \mathrm{~m}$ and $315 \mathrm{~m}$ respectively. The structures around the quarry is shown in Fig, 1 and agitating villagers in Fig. 2.

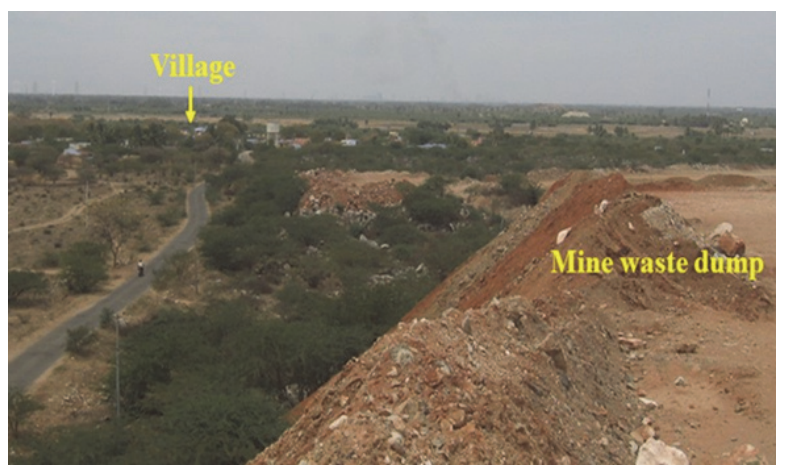

Fig. 1. Photograph showing view of the village from the quarry waste dump

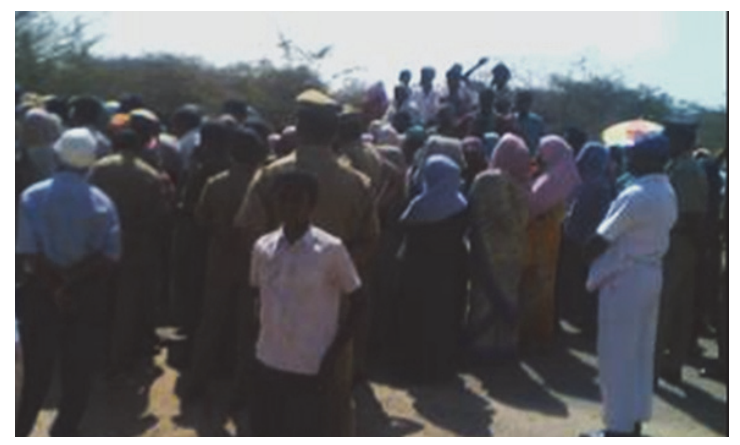

Fig. 2. Photograph showing the villagers protesting against the blasting 
The rocks in this region are metamorphosed crystalline limestone, gneisses and quartzites of Archean group. The crystalline limestone is medium to coarse grained and generally white in colour. The average grade of limestone in this deposit is $81.6 \% \mathrm{Caco} 3$ and $1.8 \% \mathrm{MgCo}$. The deposit is being worked by open pit mining method in two benches of 7 to $9 \mathrm{~m}$ in height. The benches are excavated by drilling and blasting along with in-house monitoring of ground vibration. The blasted material is transported through tippers and fed to the crusher which is located around $25 \mathrm{~km}$ from the quarry. Over burden is handled and dumped in the waste dump yard within the lease boundary.

\section{BLASTS DETAILS}

In total, twelve blasts were carried out. The first blast was carried out at the farthest location from the critical structure. These blasts were representative of the routine blasting practices that were being followed in the quarry. The holes were of $115 \mathrm{~mm}$ in diameter and drilled with crawler mounted drilling machines. The burden and spacing was $3.0 \mathrm{~m} \times 3.5 \mathrm{~m}$. The number of holes in a blast varied from 10 to 44 . The depth of the holes varied from $2.8 \mathrm{~m}$ to $9.0 \mathrm{~m}$ and the explosive used was Kelvex 800, Kelvex 600 (83 mm dia, $2.78 \mathrm{~kg}, 40 \mathrm{~cm}$ long) and ANFO. Drill cuttings were used for stemming the holes. The stemming length varied from $2.1 \mathrm{~m}$ to $3.6 \mathrm{~m}$ depending on hole depths. The charge per hole varied from $7 \mathrm{~kg}$ and 47 $\mathrm{kg}$ as per the hole. The maximum charge per delay varied between $30 \mathrm{~kg}$ and $94 \mathrm{~kg}$ and the total charge in a round varied between $250 \mathrm{~kg}$ and $2073 \mathrm{~kg}$. All the blasts were initiated with D-cord down the line and the surface hook up was through short delay electric detonator with sequential blasting machine (Table1).

TABLE I. DETAILS OF THE BLASTS CONDUCTED FOR THE STUDY

\begin{tabular}{|l|l|l|l|l|l|l|l|l|}
\hline $\begin{array}{l}\text { BL. } \\
\text { No. }\end{array}$ & $\mathbf{N}$ & $\begin{array}{l}\mathbf{D}, \\
(\mathbf{M})\end{array}$ & $\begin{array}{l}\mathbf{B}, \\
(\mathbf{M})\end{array}$ & $\begin{array}{l}\mathbf{S}, \\
(\mathbf{M})\end{array}$ & $\begin{array}{l}\mathbf{C P H}, \\
(\mathbf{K G})\end{array}$ & $\begin{array}{l}\mathbf{S T}, \\
(\mathbf{M})\end{array}$ & $\begin{array}{l}\mathbf{M C D}, \\
(\mathbf{K G})\end{array}$ & $\begin{array}{l}\text { TC, } \\
(\mathbf{K G})\end{array}$ \\
\hline 1 & 38 & 9.0 & 3.0 & 3.5 & 47 & 3.2 & 94 & 1790 \\
\hline 2 & 36 & 6.5 & 3.0 & 3.5 & 33 & 3.0 & 33 & 1200 \\
\hline 3 & 31 & 7.0 & 3.0 & 3.5 & 33 & 3.6 & 66 & 1034 \\
\hline 4 & 42 & 5.8 & 3.0 & 3.5 & 33 & 3.0 & 33 & 1223 \\
\hline 5 & 36 & 6.0 & 3.0 & 3.5 & 30 & 2.7 & 30 & 1100 \\
\hline 6 & 35 & 2.8 & 3.0 & 3.5 & 7 & 2.1 & 42 & 251 \\
\hline 7 & 41 & 7.0 & 3.0 & 3.5 & 41 & 3.1 & 41 & 1686 \\
\hline 8 & 10 & 9.0 & 3.0 & 3.5 & 46 & 3.3 & 46 & 461 \\
\hline 9 & 20 & 9.0 & 3.0 & 3.5 & 46 & 3.3 & 92 & 922 \\
\hline 10 & 44 & 9.0 & 3.0 & 3.5 & 47 & 3.0 & 94 & 2073 \\
\hline 11 & 16 & 7.0 & 3.0 & 3.5 & 35 & 2.95 & 70 & 565 \\
\hline 12 & 17 & 7.0 & 3.0 & 3.5 & 35 & 2.95 & 70 & 600 \\
\hline
\end{tabular}

N- No. of holes, D - Depth of hole, B - Burden, S - Spacing, CPH Charge per hole, St - Stemming, MCD - Maximum charge per delay, TC - Total charge.

\section{Blast VIBRATION MONITORING}

Ground vibrations were monitored using eight units of Minimate plus seismographs from Instantel, Canada. The measurement of ground vibration due to blasting was necessary so as to know whether the vibration intensities were within or higher than the prevailing norms at the third party structures. Secondly to establish the sitespecific predictor equation for estimation of permissible maximum charge per delay for future blasts in the absence of vibration monitoring so that vibration levels are within the limits. It is appropriate to mention that the accuracy of ground vibration recording is directly related to the coupling of the geophone with the ground surface. When the geophones get decoupled, the transducers move with reference to the ground surface thus increasing or decreasing the measured values. Several types of mounting methods and their effect on the measured vibration level are discussed by various researchers. During the current measurements the transducers were buried in soil to ensure good coupling. The radial distances between the blast and the monitoring station was measured using a binocular type laser based instrument.

Several equations have been proposed by various investigators to predict peak particle velocity. Among these, the equation proposed by USBM is most popular and is used in this study.

$$
\mathrm{V}=\mathrm{K}(\mathrm{D} / \sqrt{\mathrm{Q}})^{\mathrm{b}}
$$

where,

$\mathrm{V}$ is the peak particle velocity $(\mathrm{mm} / \mathrm{s})$,

$\mathrm{D}$ is the distance between the sensor and the blast ( $\mathrm{m})$,

$\mathrm{Q}$ is the maximum charge per delay $(\mathrm{kg})$,

$\mathrm{K}$ and $\mathrm{b}$ are the site constants, which can be determined by multiple regression analysis.

$\mathrm{D} / \sqrt{\mathrm{Q}}$ is called square root scaled distance

In total, 66 sets of readings were used for regression analysis. Fig. 31 shows a plot of peak particle velocity (vector sum) against square-root scaled distance on a log$\log$ graph. Based on the field data generated, the predicted mean and upper bound equations are given by

$$
\mathrm{V}=1486(\mathrm{D} / \sqrt{\mathrm{Q}})^{-1.38} \quad \text { at } 95 \% \text { confidence level }
$$

This predictor equation can be used to estimate the likely peak particle velocity associated with any given maximum charge per delay at a set distance from the location of the blast to the monitoring location or vice versa.

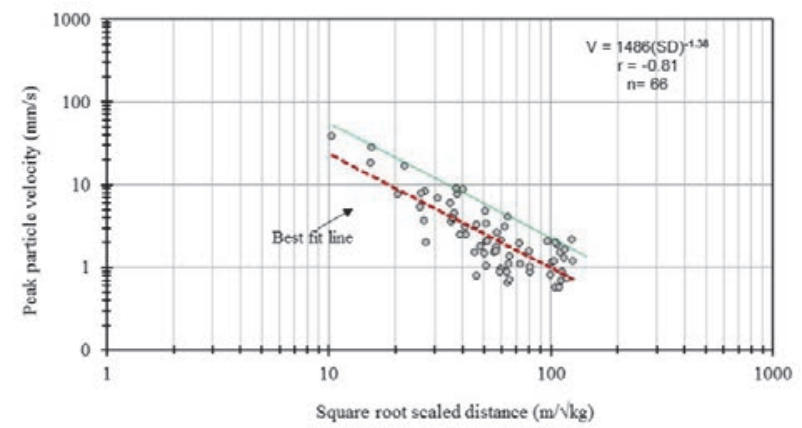

Fig.3. Peak particle velocity versus scaled distance

\section{Risk Evaluation Curve}

The log-log graph as shown in the Figure 3 is a statistical tool for establishing or predicting the vibration levels for given parameters. However, it cannot physically depict or relate the attenuation of the vibration intensities 
for the blasts conducted at the quarry with distance. Considering this, it is essential that PPV - distance graphs are to be plotted in other words "Attenuation Curve" (AE Curve - Curve 'A') and "Risk Evaluation Curve" (RE Curve - Curve 'B') be drawn to know the attenuation of PPV with distance (Figure 4). Curve " $A$ " shows the attenuation of PPV with distance as per actual measured values. However, most of the blasts are designed for the estimated maximum charge per delay based on the derived site specific predictor equation. Considering this, the authors have input the actual maximum charge per delay used during the trials with the corresponding actual distances in the site specific predictor equation to draw curve ' $\mathrm{B}$ '. This curve is termed as the "Risk Evaluation Curve" which clearly indicates to what safe distance the current blasting operations could continue from the critical structures complying to the vibration limits with the current blasting practice without any design modifications. In other words those proposed benches/current benches which fall within a noncompliance distance is termed as "Risk Zone" probably needing design modifications or complete abundance of the excavation at that location. The RE curve shall be conservative than the $\mathrm{AE}$ curve and shall account for the scatter in the field conditions and ensure that the vibration levels do not exceed the prescribed limits. For example if it is mandated to restrict the vibration levels to $10 \mathrm{~mm} / \mathrm{s}$ then it can be seen that those structure beyond a distance of $280 \mathrm{~m}$ shall not been subjected to vibration levels higher than the prescribed limits. In case, one plans to reduce the permissible limit for what so ever the reason, then the RE curve can give us the minimum safe barrier distance for compliance of the new vibration limit. From this the mine operators can plan the advancement of their benches without creating any damage to the structures.

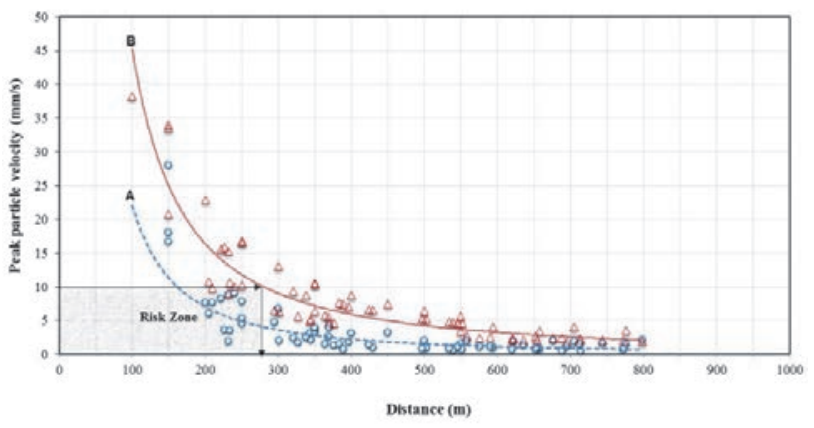

Fig. 4. Peak particle velocity versus distance

VI. FIELD READY RECKONER FOR ESTABLISHING SAFE MAXIMUM CHARGE PER DELAY OR TO Estimate THE INTENSITY OF VIBRATION

Though the derived predictor equations can be used to calculate the safe maximum charge per delay or from the scaled distance the expected PPV can be read from the graph, it is next to impossible for any blaster or a common man to do so. A minimum requirement shall be that the individual is capable of handling a scientific calculator or a spread sheet in a computer. Moreover, these are not available at the blasting location where the final hook-ups are evolved or decided at the last minute. Hence it is not uncommon to hear from the stake holders that during the site specific vibration studies the vibration levels were low and that they are back to their original once the research team left the site. Probably in some cases it may be true as the blast designers and the field personnel are not trained to compute the permissible maximum charge per delay and probably they connect the hook-up to their convenience which might have exceeded the permissible maximum charge per delay. In some cases though the maximum charge per delay might not have been calculated but still it might have been lower than the permissible charge and if there are still complaints from the stake holders or the blaster itself wants to have a feel of the probable vibration level of his design, then also there is no solution. Considering this the authors have evolved the ready reckoner concept/representation that can be universally used for arriving at the safe maximum charge per delay in the field and also for a stake holder (a house owner in the nearby village) who wants to know what would have been the vibration level that the reported maximum charge per delay has generated at his structure. These can be established from the following two data representation approaches suggested by the authors in deviation from the conventional log-log graphs or the computations from the site specific predictor equations.

\section{A. Case 1: Decision Curve or the D Curve}

Figure 5 shows the estimated PPV for the known maximum charge per delay (MCD) and distance from the site specific predictor equation. From this it becomes a handy tool for all the stake holders/blast designers/blasters to easily estimate any parameter if two of the three are known. For a blaster having known the distance from a structure (Say $250 \mathrm{~m}$ ) and the specified vibration limit (say $5 \mathrm{~mm} / \mathrm{s}$ ) it is extremely simple to arrive at the permissible mcd for his blast from the D-curve shown below $(65 \mathrm{~kg})$.

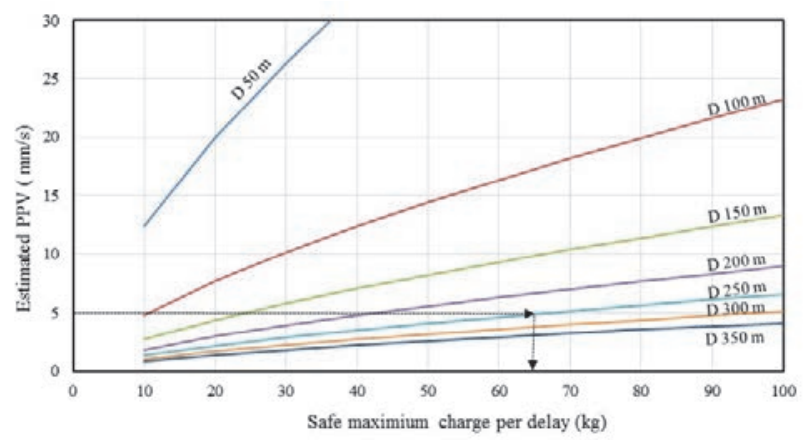

Fig. 5. PPV Estimation chart based on charge weight and distance

\section{B. Case 2: Feed Back Curve or the FB Curve}

Similarly if the blasts were designed based on the Dcurve and may be after a couple of weeks one of the stake holder complains that on such and such a day we felt the vibrations higher than the routine. In that case for him to know what could have been the vibration intensity at his structure for that blast, he simply can estimate the level from the known MCD and the distance. For example, for a MCD of $50 \mathrm{~kg}$ blasted on that day (as per records) and the distance measured or calculated from the plan (say $300 \mathrm{~m}$ ) it can be seen from Figure 6 that the vibration level has been lower than the limit of $5 \mathrm{~mm} / \mathrm{s}$ and that the blast was safe. 


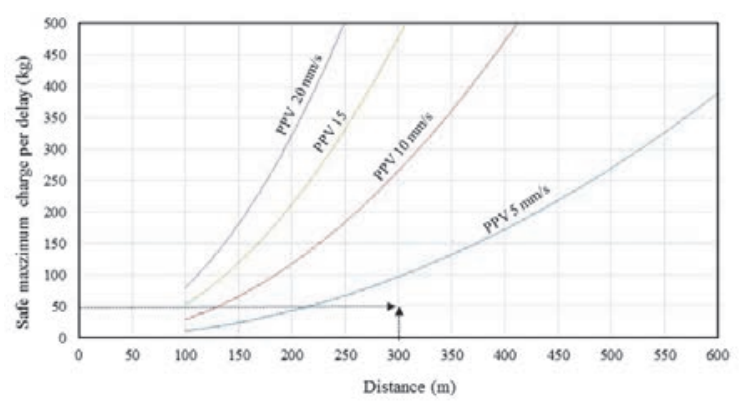

Fig. 6. Charge weight estimation based on distance (D) and PPV

\section{CONCLUSIONS}

Though vibration related issues related to blasting restrict the mining operations, it is not the end of the road. Scientific measurements combined with implementation of the outcome shall ensure the safety of the structures as well as allow the mining operations. Practical blasting charts as suggested in the paper can be prepared for all the mines and especially those facing complaints related with vibrations. The suggested approach could pave the way for many unresolved disputes to be amicably settled. The practical approach presented in the paper makes mining a socially and environmentally complying activity from those complaining as well as the implementers.

\section{ACKNOWLEDGEMENT}

The authors thank the Director, NIRM for his permission to publish this paper. The authors are also thankful to the management of Seliannallur limestone quarry, India Cements Limited for sponsoring the projects and for their co-operation extended during the field study.

\section{REFERENCES}

[1] H.S. Venkatesh, G. Gopinath, A.I. Theresraj and R. Balachander, "Ground vibration and air overpressure study due to mine blasting at Selianallur Lime stone Mine, India," NIRM Project report No. RB 08 11, 2009, (Unpublished). 